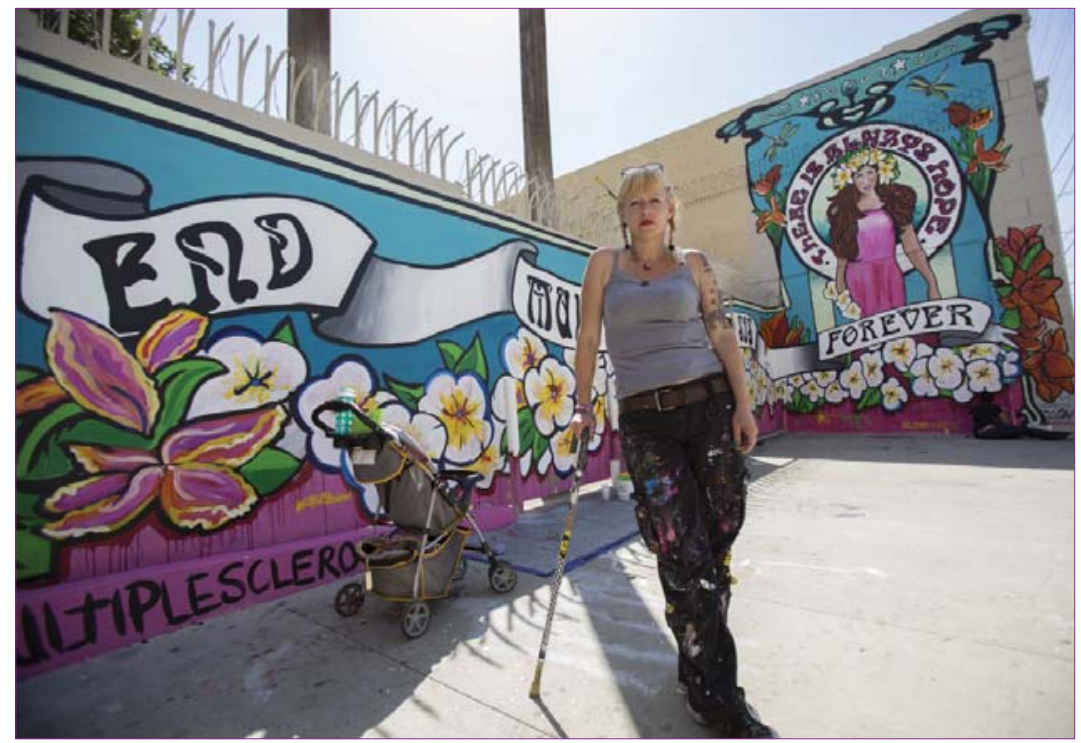

Street artist Lydia Emily Archibald, who was diagnosed with multiple sclerosis in 2012, poses by her mural aimed at raising awareness about the disease in Los Angeles, California.

Picture: Mario Anzuoni/Reuters/Picture Media

\section{From the CSIRO}

\section{Smartphone app a lifesaver for patients after myocardial infarction}

Clinical guidelines recommend that patients complete a cardiac rehabilitation program after experiencing a myocardial infarction, with studies showing that those who do have much better long-term health outcomes.

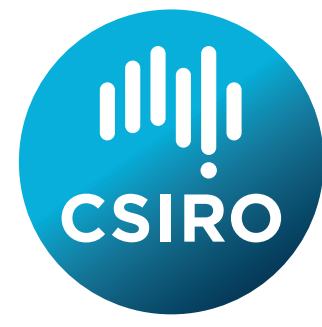

Despite the benefits, uptake of traditional cardiac rehabilitation programs is poor. Many patients find weekly travel to a health facility to be difficult. This is particularly so for those who work, care for others or live in regional Australia where these services are not available.

To overcome this problem, the Commonwealth Scientific and Industrial Research Organisation (CSIRO) and Queensland Health have developed a home-based cardiac rehabilitation program delivered via a smartphone app, called the Care Assessment Platform. This home-based program features health and exercise tools, motivational materials and multimedia delivered through the app to educate patients about disease management, and remote mentoring consultations.

A clinical trial conducted through the Australian e-Health Research Centre showed that this delivery model achieved equal or better clinical outcomes compared with a traditional rehabilitation program (Heart 2014; 100: 1770-1779). Patients recovering from myocardial infarctions were almost $30 \%$ more likely to take part in rehabilitation at home using the smartphone app, compared with those who had to travel to an outpatient clinic. Patients were also $40 \%$ more likely to adhere to the rules of the program and almost $70 \%$ more likely to complete it than those in traditional rehabilitation programs.

Most importantly, this delivery model offers a more flexible option. By integrating rehabilitation into patients' daily lives, they are more likely to complete the program and make the healthy changes to their lifestyle permanent. This overcomes one of the key barriers to patient participation and recovery.

The Care Assessment Platform will soon be offered in several Queensland hospitals. The research team is also looking to adapt the technology for use with other chronic conditions, such as pulmonary disease and diabetes.

\section{Baby teeth may predict health problems}

Examining the biochemical composition of the naturally shed baby teeth of living children could help predict future health, the Huffington Post and The Guardian report. An archaeological study of the teeth of babies who died in the Irish famine in the 1840s has revealed higher nitrogen levels than found in the bones of children who survived infancy. "The findings overturn the previous belief that high nitrogen levels are generally an indicator of good nourishment", the Huffington Post reports. Dr Julia Beaumont, from the University of Bradford, who conducted the research, wrote: "At the period we studied, it's likely that most babies were breastfed, but only some showed the spike in nitrogen isotope levels normally associated with it. Where pregnant and breast-feeding mothers are malnourished, however, they can recycle their own tissues in order for the baby to grow and then to produce milk to feed it. We believe this produces higher nitrogen isotope levels." She went on to predict that "if we can show that baby teeth, which are lost naturally, provide markers for stress in the first months of life, we could have an important indicator of future health risks, such as diabetes and heart disease."

\section{FDA takes another look at homeopathy}

The US Food and Drug Administration (FDA) is reviewing its policies in regard to the regulation of homeopathic remedies, reports NPR and CNN. In 1988 the FDA decided not to require homeopathic remedies to go through the same drug approval process as "standard medical treatments". According to a spokesperson for the FDA, Cynthia Schnedar, the FDA was revisiting the decision because of "the growing popularity of homeopathic remedies and the length of time that has passed since the agency last considered the issue", as well as concern about the quality of the remedies. CNN reports that homeopathy is a $\$ 2.9$ billion industry in the US. A systematic review by Australia's National Health and Medical Research Council, which reported that there was no evidence that homeopathic remedies worked, was tabled at a recent 2-day "listening session" held by the FDA, which plans to make a decision about labelling and regulation some time this year.

\section{Men with HIV need fewer drinks to feel effects}

Science Daily reports that researchers in the United States have found that

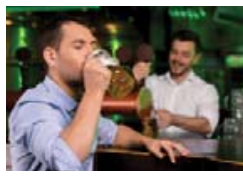

HIV-infected men are more sensitive to the effects of alcohol than uninfected men. The study published in AIDS and Behavior reviewed data on more than 2600 men enrolled in the Veterans Aging Cohort Study, an ongoing multisite study of veterans. "On average, the HIV-infected individuals with detectable virus got a buzz from imbibing just a quarter less of a drink than the others", the researchers found. "The findings suggest that there is no clearly safe level of alcohol consumption for people with $\mathrm{HIV}$, and that providers should counsel their HIV-infected patients that they are more susceptible to the harmful effects of drinking", Science Daily reports.

Cate Swannell doi: 10.5694/mjal5.n0504 


\section{Top 5 MJA articles online since 6 April 2015}

1) Perspective: Targets and abuse: the price public health campaigners pay

Public health advocates are subjected to increasing levels of abuse, some of which may be orchestrated

doi: 10.5694/mjal5.00059

2) Research: Mapping the diagnosis of autism spectrum disorders in children aged under 7 years in Australia,

2010-2012

doi: 10.5694/mja14.00328

3) Editorial: New and emerging treatments for Parkinson disease doi: 10.5694/mja15.00155

4) Editorial: Screening tests for gonorrhoea should first do no harm

doi: 10.5694/mja15.00067

5) Research: Gonorrhoea notifications and nucleic acid amplification testing in a very low-prevalence Australian female population

doi: $10.5694 / \mathrm{mj}$ al 4.00780

\section{Meanwhile, in MJA InSight . . .}

"We need to be confident that wherever a patient is [in the system], everyone is aware of what medications they are taking." - Professor Richard Day, director of clinical pharmacology and toxicology at St Vincent's Hospital, Sydney Polypharmacy a shared duty

https://www.mja.com.au/insight/2015/14/polypharmacy-shared-duty

"This current trepidation on animal models is not a fad or fringe discussion, but has found forums in well established and highly regarded scientific and medical journals." - Brett A Lidbury, associate professor with the Genomics and Predictive Medicine group at the John Curtin School of Medical Research, the Australian National University, Canberra, and a scientific advisor to Humane Research Australia

Brett Lidbury: Animal instincts

https://www.mja.com.au/insight/2015/14/brett-lidbury-animal-instincts

\section{MJA InSight Poll}

Do you think older medical students eventually make better doctors?

Total respondents: 129

Yes - maturity makes a difference

No - it makes no difference

No - it's about personal qualities

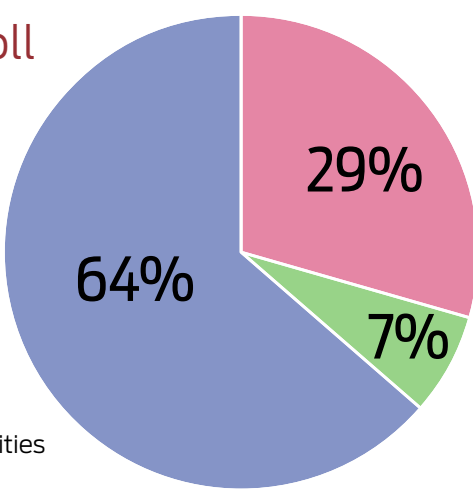

Take part in next week's poll on: www.mja.com.au/insight
MJA Comments The best Comment each month will receive $\$ 50.00$ Email a 100-word comment on any health-related topic to: comments@mja.com.au Send us your thoughts on this issue's suggested topic: What is your view on removal of the private health insurance rebate?

\section{What should be done to ensure a future for the PCEHR?}

The structure and functionality of the PCEHR must be reviewed because on current evidence it will never meet the critical requirements of health care delivery in Australia. Mamlin and Biondich (http:// www.ncbi.nlm.nih.gov/pubmed/17238397) document the essential requirements for eHealth systems. These must have the characteristics of collaboration, scalability and flexibility for the varied clinical environments coupled with rapid form design for $\mathrm{CPOE}$. They require the use of standards to support high quality research, must be webbased and support intermittent connectivity. Preferably they should be of low cost (free or open source) but the critical component is the systems must be clinically useful or they will not be used.

The PCEHR is not a clinical decision support system it is essentially a document storage system (NEHTA's own documentation) and is poorly used by clinicians and has serious issues related to patient security (https://www.mja.com.au/journal/2011/195/4/can-we-trustpcehr-not-leak).

Terry J Hannan Consultant Physician, Tas

\section{Supply and demand}

The laws of supply and demand insist that we have too few urban GPs. International comparisons or Medicare $\$ \$ \$ \$$ are proxy nonsense.

A plethora of urban GPs would ensure competition - making themselves available nights and weekends. There would be less need for people to visit the ED - they could call on their GP.

General practice is lazy urban medical practice - the hours, days or half-days which suit; forget weekends - leave a message to go to the ED. Shortage means no competition. Customers like it or lump it.

It has been thus for decades, with the AMA and the RACGP complicit.

Peter Arnold

Retired General Practitioner, NSW

\section{Medicine can be toxic}

Medicine can be toxic - strange to say, considering that it's a healing profession. The worst doctors privilege their pride (or pay) over the human suffering of patients, adopting attitudes of condescension and authoritative paternalism that I never would have expected to still exist in 21st century medicine. It is current fashion to suppress signs of such attitudes, but they persist - if not in the colour or cut of the profession, then at least in its fabric. Lip-service is paid to concepts such as medical ethics, patient autonomy and cultural sensitivity, but fundamental change remains elusory.

Congratulations: Post-doctoral Researcher Heather Sheard, from VIC, will receive $\$ 50.00$ for her comment Forgotten women doctors (MJA p351, 20 Aptil 2015).

Visit: www.mja.com.au/journal/mja-instructions-authors-types-articles-published-mja\#Comments 